\title{
Ranking facilitators and barriers of medication adherence by patients with inflammatory arthritis: a maximum difference scaling exercise
}

\author{
M. J. H. Voshaar ${ }^{1 *}$, J. E. Vriezekolk², A. M. van Dulmen ${ }^{3,4,5}$, B. J. F. van den Bemt ${ }^{6,7,8}$ and M. A. F. J. van de Laar ${ }^{9}$
}

\begin{abstract}
Introduction: Facilitators and barriers of adherence to disease-modifying anti-rheumatic drugs (DMARDs) have been identified by patients with inflammatory arthritis earlier. However, the relative importance from the patients' perspective of these factors is unknown. Knowledge on this ranking might guide the development of interventions and may facilitate targeted communication on adherence. This study aims to examine 1) the relative importance patients attach to facilitators and barriers for DMARDs adherence, and 2) the relationship between patient characteristics and ranking of these factors.

Methods: One hundred twenty-eight outpatients with inflammatory arthritis; (60\% female, mean age 62 years $(S D=12)$, median disease duration 15 years, IQR $(7,23)$ participated in a Maximum Difference scaling exercise and ranked 35 items based upon previously identified facilitators and barriers to medication adherence. Hierarchical Bayes estimation was used to compute mean Rescaled Probability Scores (RPS; 0-100) (i.e. relative importance score). Kendall's coefficient of concordance was used to examine a possible association between patients' characteristics (i.e. age, sex and educational level) and ranking of the items.
\end{abstract}

Results: The three most important items ranked by patients were: Reduction of symptoms formulated as "Arthritis medications help to reduce my symptoms" (RPS $=7.30, \mathrm{Cl} 7.17-7.44$ ), maintaining independence formulated as "I can maintain my independence as much as possible" (RPS $=6.76, \mathrm{Cl} 6.54-6.97$ ) and Shared decision making formulated as "I can decide -together with my physician- about my arthritis medications" (RPS =6.48, Cl 6.24-6.72). No associations between patient characteristics and ranking of factors were found.

Conclusions: Reducing symptoms, maintaining independency and shared decision making are patients' most important factors for DMARDs adherence. This knowledge might guide the development of interventions and may facilitate communication between health professionals and their patients on medication adherence.

Keywords: Inflammatory arthritis, Rheumatoid arthritis, Medication adherence, MaxDiff, Best-worst scaling, DMARDs use

\footnotetext{
* Correspondence: m.j.h.voshaar@utwente.nl

'Department Psychology, Health and Technology, University of Twente, Enschede, The Netherlands

Full list of author information is available at the end of the article
}

(c) The Author(s). 2021 Open Access This article is licensed under a Creative Commons Attribution 4.0 International License, which permits use, sharing, adaptation, distribution and reproduction in any medium or format, as long as you give appropriate credit to the original author(s) and the source, provide a link to the Creative Commons licence, and indicate if changes were made. The images or other third party material in this article are included in the article's Creative Commons licence, unless indicated otherwise in a credit line to the material. If material is not included in the article's Creative Commons licence and your intended use is not permitted by statutory regulation or exceeds the permitted use, you will need to obtain permission directly from the copyright holder. To view a copy of this licence, visit http://creativecommons.org/licenses/by/4.0/ The Creative Commons Public Domain Dedication waiver (http://creativecommons.org/publicdomain/zero/1.0/) applies to the data made available in this article, unless otherwise stated in a credit line to the data. 


\section{Key messages}

- Reducing symptoms, maintaining independency and shared decision making are patients' most important factors for DMARDs adherence

- Facilitators and barriers of DMARDs adherence do not seem to be related to sex, age or education

\section{Background}

Inflammatory arthritis (IA), including rheumatoid arthritis (RA), psoriatic arthritis (PsA) and ankylosing spondylitis (AS), is characterized by inflammation, impaired physical function, and ultimately progressive joint damage. New pharmacological treatments have led to improved outcomes and prevention of disability over the last decades. Obviously, disease modifying anti rheumatic drugs (DMARDs) only work if taken by a patient in accordance with the prescription. According to the World Health Organization (WHO): 'Across diseases, adherence is the most important modifiable factor that compromises treatment outcomes'. Indeed, adherence to DMARDs is still suboptimal. Non-adherence estimates between 30 and $90 \%$ [1-3], and consequently has been shown to have a negative impact on outcomes of the disease [4-6]. Adherence to treatment reflects the extent to which medication is taken as prescribed and the full benefits of DMARDs can be achieved if patients follow drug regimens [7-11]. Multiple factors have been identified that may affect medication adherence in patients with inflammatory arthritis (e.g. RA). Whereas medication beliefs, self-efficacy and the patient-clinician relationship are consistently related to medication adherence [12-16], other factors such as age, disease duration, and complexity of medication regimen show conflicting results $[2,17,18]$. Understanding which potentially modifiable factors are most important to patients and whether these factors are related to patient's characteristics is needed to develop targeted adherence interventions [2, 18-20].

In a previous qualitative study [20], we identified facilitators and barriers to DMARDs use in patients with inflammatory arthritis using an adapted version of the Theoretical Domains Framework (TDF) [21, 22]. However, the relative importance of the identified facilitators and barriers of adherence for patients with inflammatory arthritis are unknown. The ranking by patients of these factors might help communication between physicians and their patients with regard to the initiation and follow up of a DMARD-treatment. Even more, a relation between the ranking of the facilitators and barriers and patient characteristics needs to be addressed; this may be useful for the development of targeted adherence interventions.
Therefore, the aim of this study is to study the ranking by arthritis patients themselves of facilitators and barriers for DMARDs adherence, using a preference scaling methodology. In addition we aim to examine whether this ranking is associated with demographic characteristics.

\section{Methods \\ Design}

This study is a cross-sectional study, ranking the importance of previously identified facilitators and barriers for adherence to DMARDs in patients suffering from inflammatory arthritis using a Maximum Difference Scaling (MaxDiff) exercise [20]. A MaxDiff exercise (or best-worst scaling) is a method that simplifies the ranking tasks for participants and provides insight into trade-offs in the decision making process (Sawtooth Software 1 (2013) The MaxDiff system/version 8 Technical Paper. Sequim: WA, Sawtooth Software. The MaxDiff method was proved to be efficacious in similar studies in rheumatology [23-25]. This study took place in 2018-2019.

\section{Preparatory work}

For this study, facilitators and barriers for DMARD use, as identified in a previous qualitative study using focus groups and a questionnaire in patients with inflammatory rheumatic diseases was used [20]. In that study, 82 facilitators and barriers were identified, collated in the 11 domains from the adjusted Theoretical Domain Framework (TDF) [21, 22], and subsequently grouped into the higher order components Capability, Opportunity, and Motivation of the Behaviour Change Wheel $(\mathrm{BCW})$ [22]. Factors were selected from these three COM components by three researchers (MV, JV, BvdB), yielding a feasible, neutrally phrased, and representative set of 35 items related to the originally identified facilitators and barriers. The 35 items were used as input for the Maximum Difference Scaling exercise. (see Table 1).

\section{Pilot testing}

The maximum difference scaling exercise was pilot tested among a small group of patients and care providers (patients with inflammatory arthritis, $n=4$; psychologists, $n=2$; and pharmacists, $n=2$ ). Based on the pilot results, small changes in the wording of the items and the instructions were made to avoid misinterpretation.

\section{Sample size}

A standard method for sample size calculations for discrete-choice experiments is lacking [26]. Neither is there a guidelines for sample size calculations when using a maximum difference scaling method [27]. Previous MaxDiff studies reported that a minimum of 100 
Table 1 Items grouped according to TDF domains and COM components

\section{COM- Domain Item}

\section{CAPABILITY}

1 Knowledge

2 Skills

3 Memory and attention

$4 \quad$ Decision-making process

\section{MOTIVATION}

7 Beliefs about capabilities

\section{OPPORTUNITY}

5 Environmental context and resources

6 Social influences

8 Beliefs about consequences

9 Emotions

10 Motivation and goals
- My knowledge about my arthritis medication is sufficient (e.g. how the medications work, when and how often I need to take my medications)

- I understand what my treatment with medications encompasses

- The reimbursement of my arthritis medications by the health insurance company

- The way I have to administer my arthritis medications (injection or tablet)

- I can cope with my inflammatory arthritis

- I have accepted my disease

- I have accepted the need for my arthritis medications

- I can open the medication packaging

- I have good communication skills (e.g. to discuss my arthritis medications)

- The support from family and/or friends

- I can incorporate my arthritis medications into daily routines

- The name and/or appearance (colour, shape) of my arthritis medications does not change

- The support from my colleagues/supervisor in the workplace

- The availability of aids (reminders such as electronic messages) in order to take the arthritis medications as prescribed by the physician

- I can decide - together with my physician - about my arthritis medications

- The relationship with my physician

- The reimbursement of my arthritis medications by the health insurance company

- I have good communication skills (e.g. to discuss my arthritis medications)

- The relationship with my pharmacist

- I can get to my physician (accessibility, availability, timely access/when needed)

- The reimbursement of my arthritis medications by the health insurance company

- My arthritis medications are easy to use (e.g. the size of the tablet)

- The name and/or appearance (colour, shape) of my arthritis medications does not change

- It is easy to travel with my arthritis medication, e.g. to go abroad (able to keep my arthritis medications at a low temperature, clearance from customs/airline

- My arthritis medications are expensive (a burden to society)

- I can get to the pharmacy (e.g. accessibility, e.g. my arthritis medication is in stock)

- The relationship with my physician

- The reimbursement of my arthritis medications by the health insurance company

- The support from family and/or friends

- The support from my colleagues/supervisor in the workplace

- The experiences of other patients with these arthritis medications

- The relationship with my pharmacist

- My general health (apart from my inflammatory arthritis)

- There are no side effects from my arthritis medications

- I can cope with my inflammatory arthritis

- I have accepted my disease

- I have accepted the need for my arthritis medications

- I have another chronic condition (apart from my inflammatory condition)

- I can incorporate my arthritis medications into daily routines

- My arthritis medications are easy to use (e.g. the size of the tablet)

- The way I have to administer my arthritis medications (injection or tablet)

- The availability of aids (reminders such as electronic messages) in order to take the arthritis medications as prescribed by the physician

- Arthritis medications help to reduce my symptoms

- I can maintain my independence as much as possible

- I expect the arthritis medications will help to reduce my symptoms

- There are no side effects from my arthritis medications

- I have accepted my disease

- expect to be more able to participate in social activities

- I have accepted the need for my arthritis medications

- I am glad arthritis medications are available

- I am anxious about how my arthritis medications affect my body

- I am sad I have to take my arthritis medications throughout my life

- I am angry I have to take my arthritis medications throughout my life

- Arthritis medications help to reduce my symptoms 
Table 1 Items grouped according to TDF domains and COM components (Continued)

$\begin{array}{ll}\text { COM- Domain } & \text { Item } \\ \text { B } & \text { - I can maintain my independence as much as possible } \\ \text { - My general health (apart from my inflammatory arthritis) } \\ \text { - There are no side effects from my arthritis medications } \\ \text { - The relationship with my physician } \\ \text { - I have accepted my disease } \\ \text { - I have accepted the need for my arthritis medications } \\ \text { - I have another chronic condition (apart from my inflammatory condition) } \\ \text { - I can open the medication packaging } \\ \text { - I can incorporate my arthritis medications into daily routines } \\ \text { - My arthritis medications are easy to use (e.g. the size of the tablet) } \\ \text { - The way I have to administer my arthritis medications (injection or tablet) } \\ \text { - The support from my colleagues/supervisor in the workplace } \\ \text { - What the medication regimen for my arthritis medications includes (simple or complex drug regimen) } \\ \text { - The relationship with my pharmacist } \\ \text { - My general health (apart from my inflammatory arthritis) } \\ \text { - The support from family and/or friends } \\ \text { - I have another chronic condition (apart from my inflammatory condition) } \\ \text { - I can incorporate my arthritis medications into daily routines } \\ \text { - My arthritis medications are easy to use (e.g. the size of the tablet) } \\ \text { - The support from my colleagues/supervisor in the workplace } \\ \text { - The experiences of other patients with these arthritis medications } \\ \text { - The availability of aids (reminders such as electronic messages) in order to take the arthritis medications as } \\ \text { prescribed by the physician }\end{array}$

Note: Some determinants were grouped by patients under more than one domain

respondents results in a reliable assessment of preferences with the MaxDiff exercise [25]. For our study, we therefore chose to recruit a convenience sample of at least 100 consecutive patients with IA from one clinic.

\section{Patients and measures}

Patients were recruited from the rheumatology clinic (Arthritis Centre Twente, Medisch Spectrum Twente, Enschede in the Netherlands). Inclusion criteria were: 18 years or older; a diagnosis of inflammatory arthritis; using one or more DMARDs; the ability to communicate in Dutch; and informed consent. Patients with a planned visit to their rheumatologist at the hospital, were informed about this study by their rheumatologist or rheumatology nurse. If they showed interest and fulfilled the inclusion criteria, they received a letter explaining the study in more detail. The letter comprised an internet link that led them to the web-based Maximum Difference Scaling exercise, which they could complete at home. This study protocol (K17-08) was presented to the Medical Ethical Committee of the Medisch Spectrum Twente Hospital in Enschede, the Netherlands. Formal ethical approval for this study is not required under Dutch Law. Still, in accordance with the Personal Data Protection Act, informed consent was sought before the start of the Maximum Difference Scaling exercise. Taking into account an expected response rate of $20-30 \%$ [28], invitation letters were sent by mail to 450 outpatients with inflammatory arthritis using one or more DMARDs.

\section{Online survey}

The Sawtooth software's Lighthouse Studio MaxDiff 500 SSI Web version 8 was used to develop an online survey comprising a MaxDiff exercise (Sawtooth Software Inc. 2013) and a questionnaire to collect patient characteristics. In the MaxDiff exercise participants are shown several subsets of the possible items pertaining to medication adherence and are asked to indicate the most and least important item in each subset. In this study, each subset contained four items related to adherence.

Part 1 of the online survey assessed the following patient characteristics: sex, age, diagnosis, level of education, disease duration, and DMARDs use (which type of DMARD).

Part 2 of the online survey comprised the choice task using the maximum difference scaling method: 27 subsets were presented. Each subset contained four items related to DMARD use (Fig. 1). This approach simplifies the ranking tasks for participants, enables discrimination between ratings of different items involved in complex decisions and is not influenced by scale related biases [29]. Sawtooth software creates an optimal design of subsets based on 20,000 iterations of the exercise to ensure variation in the combination of items. An open link was created to be disseminated to the patients.

Each of the subsets had a different order of various items, to ensure that every participant would rank the item three times $(27 \times 4 / 35=3)$ and to avoid that higher importance was given to the first mentioned item. Participants were asked to choose the most important and the least important item, by answering the question: "In order to take my arthritis medication as prescribed by 


\section{Please read the four items below. Indicate which item is (or was) most important, and which item is (or was) least important when considering the use of your DMARD medications as prescribed by your physician}

\section{Question (22 of 27)}

\begin{tabular}{|c|c|c|}
\hline $\begin{array}{c}\text { Most } \\
\text { important }\end{array}$ & & $\begin{array}{c}\text { Least } \\
\text { important }\end{array}$ \\
\hline$\bigcirc$ & That I can decide - in shared collaboration with my physician - about my arthritis medications & $\bigcirc$ \\
\hline$\bigcirc$ & That I can get to the pharmacy (e.g. accessibility, e.g. my arthritis medication is in stock) & $\bigcirc$ \\
\hline$\bigcirc$ & That I am glad arthritis medications are available & $\bigcirc$ \\
\hline$\bigcirc$ & That I can maintain my independence as much as possible & $\bigcirc$ \\
\hline
\end{tabular}

Click on the arrow to continue

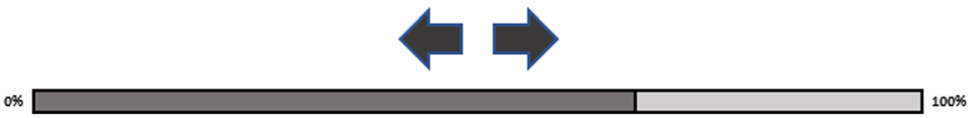

Fig. 1 Example of a MaxDiff question

my physician, which item is/was most/least important to me?"

\section{Statistical analysis}

Descriptive analyses were used to describe patient characteristics. Where appropriate, mean and standard deviation (normally distributed continuous variables), median and interquartile range (25th-75th percentile; not normally distributed continuous variables), or percentages (binary variables) were calculated. Level of education was categorized according to the International Standard Classification of Education (ISCED). To enhance international comparability, three broad groups of educational categories were constructed: no or preprimary education, primary education and lower secondary education (ISCED 0-2); upper secondary education (ISCED 3-4); and tertiary education (ISCED 5-6). Age was grouped into tertiles (0-58/59-68/69-84 years old). The rank order and the relative importance of each item were generated by the Sawtooth software's Lighthouse Studio, using hierarchical Bayes modelling. To facilitate interpretation, the scores were rescaled to a Rescaled Probability Score (RPS) on a scale from 0 to 100: the higher the score, the more important the item. (Sawtooth Software 1 (2013) The MaxDiff System/version 8 Technical Paper. Sequim: WA, Sawtooth Software, 2013). The rescaled probability scores added up to a value of 100, which reflects the relative importance of the item. Patients that gave inconsistent answers on the maximum difference scaling exercise (Root Likelihood below the recommended cut-off of 0.336 ) were excluded from the analysis. To explore a possible association between the ranking of the RPS scores and patients' characteristics (i.e., sex, age, educational level), Kendall's coefficient of concordance (Kendall's W) was computed [30]. Kendall's W, a non-parametric statistic, is used to determine the degree of agreement between groups when working with ranked data at an ordinal level of measurement. It is a normalization of the statistic of the Friedman test, and can be used for assessing agreement among raters. Kendall's $W$ ranges from 0 (no agreement) to 1 (complete agreement). A $p$-value $<0.05$ allows to reject the null hypothesis that there is no agreement in ranking between groups. SPSS version 24.0 was used.

\section{Results}

A total of 128 patients took part in the maximum difference exercise (response rate 28\%). Three patients had a RLH below 0.336 and were therefore excluded from the analyses. Table 2 shows the characteristics of the participants. Most participating patients were women (60\%) and most participating patients had rheumatoid arthritis (89\%). The median disease duration was 15 years, IQR $(7,23)$. These patient characteristics were not significantly different from the former study in which the items were identified [20].

In Table 3, the 35 items with their relative probability score are displayed and grouped according the COM-B model. The five highest ranked items were: "Arthritis medications help to reduce my symptoms" (RPS $=7.30$, CI 7.17-7.44), "I can maintain my independence as much as possible" (RPS $=6.76, \mathrm{CI} 6.54-6.97)$ and "I can 
Table 2 Sample characteristics

\begin{tabular}{|c|c|}
\hline & IA Patients $(N=125)$ \\
\hline Age, years (mean, SD) & $62.7( \pm 12)$ \\
\hline \multicolumn{2}{|l|}{ Sex } \\
\hline Female & $75(60 \%)$ \\
\hline \multicolumn{2}{|l|}{ Diagnosis } \\
\hline Rheumatoid arthritis & $111(88.8 \%)$ \\
\hline Ankylosing Spondylitis & $4(3.2 \%)$ \\
\hline Psoriatic Arthritis & $7(5.6 \%)$ \\
\hline Other diagnoses & $3(2.4 \%)$ \\
\hline \multicolumn{2}{|l|}{ Level of education } \\
\hline No or pre-primary education & $38(30.6 \%)$ \\
\hline Primary education and lower secondary education & $42(33.9 \%)$ \\
\hline Upper secondary education and tertiary education & $44(35.5 \%)$ \\
\hline Disease duration, years (median, IQR) & $15(7,23)$ \\
\hline \multicolumn{2}{|l|}{ Pharmacotherapy } \\
\hline Methotrexate (subcutaneous) & $22(17.6 \%)$ \\
\hline Methotrexate (oral) & $64(51.2 \%)$ \\
\hline Leflunomide & $3(2.4 \%)$ \\
\hline Hydroxychloroquine & $29(23.2 \%)$ \\
\hline Sulfasalazine & $13(10.4 \%)$ \\
\hline Gold (oral) & $1(0.8 \%)$ \\
\hline Infliximab & $2(1.6 \%)$ \\
\hline Etanercept & $15(12 \%)$ \\
\hline Adalimumab & $7(5.6 \%)$ \\
\hline Rituximab & $6(4.8 \%)$ \\
\hline Abatacept & $5(4 \%)$ \\
\hline Tocilizumab & 11 (8.8\%) \\
\hline
\end{tabular}

IA Inflammatory arthritis; SD Standard deviation

decide -together with my physician- about my arthritis medications" (RPS $=6.48$, CI 6.24-6.72), "My general health (apart from IA)" (RPS $=6.42$, CI 6.08-6.76), and "I expect the arthritis medications will help to reduce my symptoms" (RPS $=6.32$, CI 6.10-6.55).

The five least important items were: "What the medication regimen for my arthritis medications includes (simple or complex drug regimen)" (RPS $=0.55$, CI 0.48-0.64), "I am sad I have to take my arthritis medications throughout my life" (RPS $=0.34$, CI 0.24-0.45), "I am angry that I have to take my arthritis medications throughout my life" $(\mathrm{RPS}=0.26$, CI $0.18-0.33)$, "The relationship with my pharmacist" (RPS $=0.24$, CI $0.15-0.33$ ), "The availability of aids (reminders such as electronic messages) in order to take the arthritis medications as prescribed by the physician" (RPS $=0.23$, CI 0.17-0.30).

\section{Agreement in ranking between patient subgroups}

Kendall's W analyses showed that all subgroups ranked the items at a high level of agreement (Kendall's W ranged between .97 to .99 for sex $(p=.000)$, age $(\mathrm{p}=$ $.000)$ and level of education $(p=.001)$ ) indicating that no significant difference based on sex, age or level of education, in ranking the relative importance of items important to adherence were found. Kendall's $W$ ranges from 0 (no agreement) to 1 (complete agreement). A $p$-value < .05 allows to reject the null hypothesis that there is no agreement in ranking between groups.

\section{Discussion}

This study ranked the earlier identified facilitators and barriers of adherence to arthritis medication by patients. The five highest ranked items are "Arthritis medications help to reduce my symptoms", "I can maintain my independence as much as possible", "I can decide -together with my physician- about my arthritis medications", "My general health (apart from IA)", and "I expect the arthritis medications will help to reduce my symptoms". All these factors are related to reducing symptoms, maintaining independency and shared decision making. The 
Table 3 Ranking of items based on Rescaled Probability Score (RPS)

\begin{tabular}{ll}
\hline Ranking & Description \\
\hline 1 & Arthritis medications help to reduce my symptoms \\
2 & I can maintain my independence as much as possible \\
3 & I can decide - together with my physician - about my arthritis medications \\
4 & My general health (apart from my inflammatory arthritis) \\
5 & I expect the arthritis medications will help to reduce my symptoms \\
6 & I am glad arthritis medications are available \\
7 & There are no side effects from my arthritis medications \\
8 & I can cope with my inflammatory arthritis \\
9 & The relationship with my physician
\end{tabular}

10
I can get to my physician (accessibility, availability, timely access/when needed)

My knowledge about my arthritis medications is sufficient (e.g. how the medications work, when and how often I need to take my medications)

I have accepted my disease

I understand what my treatment with medications encompasses

I am anxious about how my arthritis medications affect my body

I expect to be more able to participate in social activities

The reimbursement of my arthritis medications by the health insurance company

I have accepted the need for my arthritis medications

The support from family and/or friends

I have another chronic condition (apart from my inflammatory condition)

I can open the medication packaging

I can incorporate my arthritis medications into daily routines

My arthritis medications are easy to use (e.g. the size of the tablets)

The name and/or appearance (color, shape) of my arthritis medications does not change

It is easy to travel with my arthritis medications, e.g. go abroad (able to keep my arthritis medications at a low temperature, clearance from customs/airline)

My arthritis medications are expensive (a burden to society)

I can get to the pharmacy (e.g. accessibility, e.g. my arthritis medication is in stock)

I have good communication skills (e.g. to discuss my arthritis medications)

The way I have to administer my arthritis medications (injection or tablet)

The support from my colleagues/supervisor in the workplace

The experiences of other patients with these arthritis medications

What the medication regimen for my arthritis medications includes (simple or complex drug regimen)

I am sad I have to take my arthritis medications throughout my life

I am angry that I have to take my arthritis medications throughout my life
COM component (numbers: see Table 1)

Motivation: 8/10

Motivation: $8 / 10$

Capability: 4

Motivation: 7/10/11

Motivation: 8

Motivation: 9

Motivation: 7/8/10

Capability and Motivation:

$7 / 2$

Capability, Opportunity and Motivation: 4/6/10

Opportunity: 5

Capability: 1

Capability and Motivation: $7 / 8 / 10 / 2$

Capability: 1

Motivation: 9

Motivation: 8

Capability and Opportunity: 1/4/6/5

Capability and Motivation: 7/8/10/2

Capability, Opportunity and Motivation: 3/6/11

Motivation: 7/10/11

Capability and Motivation: 10/2

Capability and Motivation: 3/7/10/11

Capability, Opportunity and Motivation:7/10/11/5

Capability and Opportunity $3 / 5$

Opportunity: 5

Opportunity: 5

Opportunity: 5

Capability: 4/2

Capability and Motivation: 1/7/10

Capability, Opportunity and Motivation: 6/10/11

Capability, Opportunity and Motivation: 6/11

Motivation: 10

Motivation: 9

\section{RPS $\mathrm{Cl} \quad \mathrm{Cl}$}

lower upper

$\begin{array}{lll}7.30 & 7.17 & 7.44\end{array}$

$\begin{array}{lll}6.76 & 6.54 \quad 6.97\end{array}$

$\begin{array}{lll}6.48 & 6.24 & 6.72\end{array}$

$6.42 \quad 6.08 \quad 6.76$

$\begin{array}{lll}6.32 & 6.10 \quad 6.55\end{array}$

$\begin{array}{lll}6.16 & 5.93 \quad 6.40\end{array}$

$\begin{array}{lll}5.46 & 5.11 \quad 5.82\end{array}$

$\begin{array}{lll}5.43 & 5.11 \quad 5.76\end{array}$

$5.38 \quad 5.10 \quad 5.66$

$\begin{array}{lll}4.87 & 4.54 \quad 5.19\end{array}$

$\begin{array}{lll}4.16 & 3.87 \quad 4.46\end{array}$

$\begin{array}{lll}3.99 & 3.60 \quad 4.38\end{array}$

$\begin{array}{lll}3.79 & 3.49 \quad 4.09\end{array}$

$\begin{array}{lll}3.00 & 2.59 \quad 3.40\end{array}$

$2.90 \quad 2.59 \quad 3.22$

$\begin{array}{lll}2.75 & 2.30 \quad 3.20\end{array}$

$2.41 \quad 2.14 \quad 2.67$

$\begin{array}{lll}2.37 & 2.03 \quad 2.72\end{array}$

$1.74 \quad 1.43 \quad 2.05$

$\begin{array}{lll}1.63 & 1.36 & 1.91\end{array}$

$1.45 \quad 1.24 \quad 1.66$

$\begin{array}{lll}1.15 & 0.92 \quad 1.38\end{array}$

$\begin{array}{lll}0.97 & 0.64 & 1.31\end{array}$

$\begin{array}{lll}0.93 & 0.67 \quad 1.19\end{array}$

$\begin{array}{lll}0.90 & 0.67 & 1.12\end{array}$

$\begin{array}{lll}0.84 & 0.69 & 1.00\end{array}$

$\begin{array}{lll}0.82 & 0.69 & 0.95\end{array}$

$\begin{array}{lll}0.76 & 0.61 \quad 0.90\end{array}$

$\begin{array}{lll}0.63 & 0.47 & 0.79\end{array}$

$\begin{array}{lll}0.62 & 0.47 \quad 0.76\end{array}$

$\begin{array}{lll}0.55 & 0.46 \quad 0.64\end{array}$

$\begin{array}{lll}0.26 & 0.18 & 0.33\end{array}$ 
Table 3 Ranking of items based on Rescaled Probability Score (RPS) (Continued)

\begin{tabular}{|c|c|c|c|c|c|}
\hline Ranking & Description & $\begin{array}{l}\text { COM component } \\
\text { (numbers: see Table 1) }\end{array}$ & RPS & $\begin{array}{l}\mathrm{Cl} \\
\text { lower }\end{array}$ & $\begin{array}{l}\text { Cl } \\
\text { upper }\end{array}$ \\
\hline 34 & The relationship with my pharmacist & $\begin{array}{l}\text { Capability, Opportunity and } \\
\text { Motivation: } 4 / 6 / 10\end{array}$ & 0.24 & 0.15 & 0.33 \\
\hline 35 & $\begin{array}{l}\text { The availability of aids (reminders such as electronic messages) in order to take the } \\
\text { arthritis medications as prescribed by the physician }\end{array}$ & $\begin{array}{l}\text { Capability and Motivation: } \\
3 / 7 / 11\end{array}$ & 0.23 & 0.17 & 0.29 \\
\hline
\end{tabular}

RPS Rescaled Probability Score; $\mathrm{Cl}$ Confidence Interval

five least important ranked items were: "What the medication regimen for my arthritis medications includes (simple or complex drug regimen)", "I am sad I have to take my arthritis medications throughout my life", "I am angry that I have to take my arthritis medications throughout my life", "The relationship with my pharmacist", "The availability of aids (reminders such as electronic messages) in order to take the arthritis medications as prescribed by the physician", suggesting practical issues are least important for arthritis patients in order to adhere to medication in this study. Categorising patients' top five items according to the COM-B model reveals that four of the five highest ranked items are related to patient's motivation, whereas one determinant is related to patient's capabilities.

Our results are in line with a recently published qualitative focus group study using nominal group technique [31]. Although this latter study had an inductive approach and was consequently not based on a theoretical model, several findings were comparable. Items like the importance of patient-physician interaction and efficacy of medication were ranked high. Our study also indicated the absence of a relation between ranking of factors pertaining to adherence and demographics: sex, age and education.

Our study also confirmed that patients prefer to discuss and decide the choice of medications in close collaboration with their physician [32-34]. Patients are also more likely to adhere to a treatment that matches their preferences [35]. Tailoring treatment to patients' medication preferences shows to be a promising strategy to improve adherence [28]. Therefore, providing the patient with unambiguous, high quality information [36] creates optimal circumstances for adherence to medication. Although practical issues such as the availability of aids to facilitate adherence were in this study ranked relatively low, such aids (e.g., application of electronic messages or reminders) can have a significant effect on adherence [37].

\section{Strengths and limitations}

This study is the first patient oriented and theory based study ranking facilitators and barriers for adherence that can help for the development of targeted interventions to improve adherence. These findings are helpful information for healthcare professionals to guide the conversation on adherence with their patients. The mentioned factors influencing adherent behaviour can be used as a checklist for both the health professional and the patient to discuss potential adherence problems when needed. The factors ranked as most important were related to patients' motivation, indicating that motivational support, such as motivational interviewing, could be useful to enhance adherence [38]. Furthermore, the findings of this study can be used for the development of future adherence interventions. There are some limitations in this study. The first limitation is that a selection bias in the recruitment process could have occurred. One may assume that more motivated patients, and more adherent patients were inclined to participate in this study. However, our study sample was representative for patients with inflammatory arthritis using DMARDs in the Netherlands. The second limitation is that all items related to facilitators and barriers needed to be rephrased. Obviously, rephrasing was necessary to reduce bias by using neutral wordings taking away any positive or negative valence of each facilitators and barriers [39, 40]. Most patients included in this mono centre study had rheumatoid arthritis, used conventional synthetic DMARDs (csDMARDs) or biological DMAR Ds (bDMARDS), and had a long disease duration, limiting the generalization of our findings. Furthermore, patients with different levels of disease activity, with different routes of administration or with comorbidities may also rank these items differently.

To examine whether the outcome of the ranking process differs in subgroup of patients (e.g., other rheumatic conditions, other DMARDs such as targeted synthetic DMARDs (tsDMARDs), patients with short disease duration, patients with different levels of disease activity) or in other countries (e.g., with different healthcare systems and insurances), future research is warranted.

\section{Conclusions}

Our study showed the ranking of adherence-related factors by patients with inflammatory arthritis. Reducing symptoms, maintaining independency and shared decision making are considered most important for DMAR Ds adherence by patients. This finding can be of value to 
enhance communication between healthcare professionals and patients. When health professionals give attention to these items in their conversation with patients, adherence might be enhanced. Furthermore, the results are useful information for the development of interventions to optimize DMARDs adherence in IA patients. Since most highly ranked items are related to motivation according to the COM-B model, it might be useful to focus on the development of adherence interventions that capture motivational components.

\section{Abbreviations \\ DMARDs: Disease-modifying anti-rheumatic drugs; TDF: Theoretical domains framework; IA: Inflammatory arthritis; RA: Rheumatoid arthritis; TDF: Theoretical domains framework; MaxDiff: Maximum difference scaling exercise; RPS: Rescaled probability score; BCW: Behaviour change wheel; COM-B model: Capability, opportunity and motivation-behaviour model (based on the behaviour change wheel); Kendall's W: Kendall's coefficient of concordance; SPSS: Statistical package for the social sciences; RLH: Root likelihood; SD: Standard deviation; Cl: Confidence interval}

\section{Acknowledgements}

The authors would like to thank all participants who completed the exercise. The Sawtooth software's Lighthouse Studio was used, offered as a grant for which the authors are grateful.

\section{Authors' contributions}

$\mathrm{MV}, \mathrm{BVB}$, and JV were involved in the study conceptualisation and design, data collection, data analysis and interpretation, and drafting the manuscript. SvD and MvdL were involved in the study design, data analysis and interpretation, and drafting of the manuscript. All authors read and corrected the concepts and approved the final manuscript.

\section{Funding}

Not applicable.

\section{Availability of data and materials}

Due to the nature of the study, any information that could identify participants is not available. Further information is available by application to the corresponding author.

\section{Ethics approval and consent to participate}

Under Dutch law, this study did not need formal approval from an Ethical Review Board. Written informed consent was obtained from patients, before participating in the MaxDiff study.

\section{Consent for publication}

Patients have given their consent online in the maximum difference exercise, to use their data, the results of the ranking exercise, resulting in this article.

\section{Competing interests}

The authors declare that they have no competing interests.

\section{Author details}

${ }^{1}$ Department Psychology, Health and Technology, University of Twente, Enschede, The Netherlands. ${ }^{2}$ Department of Rheumatology, Sint Maartenskliniek, Nijmegen, The Netherlands. ${ }^{3}$ Nivel (Netherlands Institute for Health Services Research), Utrecht, The Netherlands. ${ }^{4}$ Department of Primary and Community Care, Radboud University Medical Centre, Radboud Institute for Health Sciences, Nijmegen, The Netherlands. ${ }^{5}$ Faculty of Health and Social Sciences, University of South- Eastern Norway, Drammen, Norway.

${ }^{6}$ Department of Pharmacy, Sint Maartenskliniek, Nijmegen, The Netherlands. 7Department of Pharmacy, RadboudUMC, Nijmegen, The Netherlands. ${ }^{8}$ Department of Clinical Pharmacy and Toxicology, Maastricht University Medical Centre, Maastricht, The Netherlands. ${ }^{9}$ Arthritis Centre Twente, Medisch Spectrum Twente \& University of Twente, P.O box 50,000, 7500, KA, Enschede, The Netherlands.
Received: 4 March 2020 Accepted: 14 December 2020

Published online: 06 January 2021

\section{References}

1. Harrold LR, Andrade SE. Medication adherence of patients with selected rheumatic conditions: a systematic review of the literature. Semin Arthritis Rheum. 2009;38(5):396-402. https://doi.org/10.1016/j.semarthrit.2008.01.011.

2. Pasma A, van't Spijker A, Hazes JM, Busschbach JJ, Luime JJ. Factors associated with adherence to pharmaceutical treatment for rheumatoid arthritis patients: a systematic review. Semin Arthritis Rheum. 2013;43(1):1828. https://doi.org/10.1016/.jsemarthrit.2012.12.001.

3. van den Bemt $\mathrm{BJ}$, Zwikker $\mathrm{HE}_{\text {, van }}$ den Ende $\mathrm{CH}$. Medication adherence in patients with rheumatoid arthritis: a critical appraisal of the existing literature. Expert Rev Clin Immunol. 2012;8(4):337-51. https://doi.org/10. 1586/eci.12.23.

4. Bluett J, Morgan C, Thurston L, Plant D, Hyrich KL, Morgan AW, Barton A. Impact of inadequate adherence on response to subcutaneously administered anti-tumour necrosis factor drugs: results from the biologics in rheumatoid arthritis genetics and genomics study syndicate cohort. Rheumatology (Oxford). 2015;54(3):494-9. https://doi.org/10.1093/ rheumatology/keu358.

5. Viller F, Guillemin F, Briancon S, Moum T, Suurmeijer T, van den Heuvel W. Compliance to drug treatment of patients with rheumatoid arthritis: a 3 year longitudinal study. J Rheumatol. 1999;26(10):2114-22.

6. Waimann CA, Marengo MF, de Achaval S, Cox VL, Garcia-Gonzalez A, Reveille JD, Suarez-Almazor ME. Electronic monitoring of oral therapies in ethnically diverse and economically disadvantaged patients with rheumatoid arthritis: consequences of low adherence. Arthritis Rheum. 2013: 65(6):1421-9. https://doi.org/10.1002/art.37917.

7. Chambers SA, Rahman A, Isenberg DA. Treatment adherence and clinical outcome in systemic lupus erythematosus. Rheumatology (Oxford). 2007; 46(6):895-8. https://doi.org/10.1093/rheumatology/kem016.

8. Darmawan J, Rasker JJ, Nuralim H. Reduced burden of disease and improved outcome of patients with rheumatoid factor positive rheumatoid arthritis compared with dropouts. A 10 year observational study. J Rheumatol Suppl. 2003;67:50-3.

9. Julian LJ, Yelin E, Yazdany J, Panopalis P, Trupin L, Criswell LA, Katz P. Depression, medication adherence, and service utilization in systemic lupus erythematosus. Arthritis Rheum. 2009;61 (2):240-6. https://doi.org/10.1002/ art.24236.

10. Newsome G. Guidelines for the management of rheumatoid arthritis: 2002 update. J Am Acad Nurse Pract. 2002;14(10):432-7.

11. Smolen JS, Landewe R, Bijlsma J, Burmester G, Chatzidionysiou K, Dougados $M$, et al. EULAR recommendations for the management of rheumatoid arthritis with synthetic and biological disease-modifying antirheumatic drugs: 2016 update. Ann Rheum Dis. 2017;76(6):960-77. https://doi.org/10. 1136/annrheumdis-2016-210715.

12. de Thurah A, Norgaard M, Harder I, Stengaard-Pedersen K. Compliance with methotrexate treatment in patients with rheumatoid arthritis: influence of patients' beliefs about the medicine. A prospective cohort study. Rheumatol Int. 2010;30(11):1441-8. https://doi.org/10.1007/s00296-009-1160-8.

13. Hope HF, Hyrich KL, Anderson J, Bluett J, Sergeant JC, Barton A, et al. The predictors of and reasons for non-adherence in an observational cohort of patients with rheumatoid arthritis commencing methotrexate. Rheumatology (Oxford). 2020;59(1):213-23. https://doi.org/10.1093/ rheumatology/kez274.

14. Neame R, Hammond A. Beliefs about medications: a questionnaire survey of people with rheumatoid arthritis. Rheumatology (Oxford). 2005;44(6):762-7. https://doi.org/10.1093/rheumatology/keh587.

15. Treharne GJ, Lyons AC, Kitas GD. Medication adherence in rheumatoid arthritis: effects of psychosocial factors. Psychol Health Med. 2004;9(3):33749. https://doi.org/10.1080/13548500410001721909.

16. van den Bemt BJ, van den Hoogen FH, Benraad B, Hekster YA, van Riel PL, van Lankveld W. Adherence rates and associations with nonadherence in patients with rheumatoid arthritis using disease modifying antirheumatic drugs. J Rheumatol. 2009;36(10):2164-70. https://doi.org/10.3899/jrheum. 081204

17. Curtis JR, Bykerk VP, Aassi M, Schiff M. Adherence and persistence with methotrexate in rheumatoid arthritis: a systematic review. J Rheumatol. 2016;43(11):1997-2009. https://doi.org/10.3899/jrheum.151212. 
18. Wong PK. Medication adherence in patients with rheumatoid arthritis: why do patients not take what we prescribe? Rheumatol Int. 2016;36(11):153542. https://doi.org/10.1007/s00296-016-3566-4.

19. Delestras S, Roustit M, Bedouch P, Minoves M, Dobremez V, Mazet R, et al. Comparison between two generic questionnaires to assess satisfaction with medication in chronic diseases. PLoS One. 2013;8(2):e56247. https://doi.org/ 10.1371/journal.pone.0056247.

20. Voshaar MJH, Vriezekolk J, van Dulmen S, van den Bemt B, van de Laar M. Barriers and facilitators to disease-modifying antirheumatic drug use in patients with inflammatory rheumatic diseases: a qualitative theory-based study. BMC Musculoskelet Disord. 2016;17(1):442. https://doi.org/10.1186/ s12891-016-1289-z.

21. Easthall, C. (2012). Developing the identification of medication adherence barriers (IMAB) instrument; a novel applicatio of behaviour change theoretical frameworks.

22. Michie S, Johnston M, Abraham C, Lawton R, Parker D, Walker A. Making psychological theory useful for implementing evidence based practice: a consensus approach. Qual Saf Health Care. 2005;14(1):26-33. https://doi.org/ 10.1136/qshc.2004.011155.

23. Meyfroidt S, Hulscher M, De Cock D, Van der Elst K, Joly J, Westhovens R, Verschueren $\mathrm{P}$. A maximum difference scaling survey of barriers to intensive combination treatment strategies with glucocorticoids in early rheumatoid arthritis. Clin Rheumatol. 2015;34(5):861-9. https://doi.org/10.1007/s10067015-2876-3.

24. van Hulst $L T$, Kievit W, van Bommel R, van Riel PL, Fraenkel L. Rheumatoid arthritis patients and rheumatologists approach the decision to escalate care differently: results of a maximum difference scaling experiment. Arthritis Care Res (Hoboken). 2011;63(10):1407-14. https://doi.org/10.1002/ acr.20551.

25. Verhoef LM, Selten EMH, Vriezekolk JE, de Jong AJL, van den Hoogen FHJ, den Broeder AA, Hulscher ME. The patient perspective on biologic DMARD dose reduction in rheumatoid arthritis: a mixed methods study. Rheumatology (Oxford). 2018;57(11):1947-55. https://doi.org/10.1093/ rheumatology/key205.

26. de Bekker-Grob EW, Donkers B, Jonker MF, Stolk EA. Sample size requirements for discrete-choice experiments in healthcare: a practical guide. Patient. 2015;8(5):373-84. https://doi.org/10.1007/s40271-015-0118-z.

27. Cheung KL, Wijnen BF, Hollin IL, Janssen EM, Bridges JF, Evers SM, Hiligsmann M. Using best-worst scaling to investigate preferences in health care. Pharmacoeconomics. 2016;34(12):1195-209. https://doi.org/10.1007/ s40273-016-0429-5.

28. van Heuckelum M, Mathijssen EG, Vervloet M, Boonen A, Hebing RC, Pasma $A$, et al. Preferences of patients with rheumatoid arthritis regarding diseasemodifying antirheumatic drugs: a discrete choice experiment. Patient Prefer Adherence. 2019;13:1199-211. https://doi.org/10.2147/ppa.s204111.

29. Muhlbacher AC, Kaczynski A, Zweifel P, Johnson FR. Experimental measurement of preferences in health and healthcare using best-worst scaling: an overview. Health Econ Rev. 2016;6(1):2. https://doi.org/10.1186/ s13561-015-0079-x.

30. Legendre P. Species associations: the Kendall coefficient of concordance revisited. J Agric Biol Environ Stat. 2005;10(2):226-45. https://doi.org/10. 1198/108571105X46642.

31. Kelly A, Tymms K, de Wit M, Bartlett SJ, Cross M, Dawson T, et al. Patient and caregiver priorities for medication adherence in gout, osteoporosis and rheumatoid arthritis: nominal group technique. Arthritis Care Res (Hoboken). 2019. https://doi.org/10.1002/acr.24032.

32. Levinson W, Kao A, Kuby A, Thisted RA. Not all patients want to participate in decision making. A national study of public preferences. J Gen Intern Med. 2005;20(6):531-5. https://doi.org/10.1111/j.1525-1497.2005.04101.x.

33. Nota I, Drossaert CH, Taal E, van de Laar MA. Arthritis patients' motives for (not) wanting to be involved in medical decision-making and the factors that hinder or promote patient involvement. Clin Rheumatol. 2016;35(5): 1225-35. https://doi.org/10.1007/s10067-014-2820-y.

34. Schildmann J, Grunke M, Kalden JR, Vollmann J. Information and participation in decision-making about treatment: a qualitative study of the perceptions and preferences of patients with rheumatoid arthritis. J Med Ethics. 2008;34(11):775-9. https://doi.org/10.1136/jme.2007.023705.

35. Laba TL, Essue B, Kimman M, Jan S. Understanding patient preferences in medication nonadherence: a review of stated preference data. Patient. 2015; 8(5):385-95. https://doi.org/10.1007/s40271-014-0099-3.
36. Mathijssen EG, Vriezekolk JE, Eijsbouts AM, van den Hoogen FH, van den Bemt BJ. Support needs for medication use and the suitability of eHealth technologies to address these needs: a focus group study of older patients with rheumatoid arthritis. Patient Prefer Adherence. 2018;12:349-58. https:// doi.org/10.2147/ppa.s152759.

37. van Heuckelum M, van den Ende CHM, Houterman AEJ, Heemskerk CPM, van Dulmen S, van den Bemt BJF. The effect of electronic monitoring feedback on medication adherence and clinical outcomes: a systematic review. PLoS One. 2017;12(10):e0185453. https://doi.org/10.1371/journal. pone.0185453.

38. Palacio A, Garay D, Langer B, Taylor J, Wood BA, Tamariz L. Motivational interviewing improves medication adherence: a systematic review and meta-analysis. J Gen Intern Med. 2016;31(8):929-40. https://doi.org/10.1007/ s11606-016-3685-3.

39. Pengo MF, Czaban M, Berry MP, Nirmalan P, Brown R, Birdseye A, et al. The effect of positive and negative message framing on short term continuous positive airway pressure compliance in patients with obstructive sleep apnea. J Thorac Dis. 2018;10(Suppl 1):S160-s169. https://doi.org/10.21037/ jtd.2017.07.110.

40. Veldwijk J, Essers BA, Lambooij MS, Dirksen CD, Smit HA, de Wit GA. Survival or mortality: does risk attribute framing influence decision-making behavior in a discrete choice experiment? Value Health. 2016;19(2):202-9. https://doi. org/10.1016/j.jval.2015.11.004.

\section{Publisher's Note}

Springer Nature remains neutral with regard to jurisdictional claims in published maps and institutional affiliations.
Ready to submit your research? Choose BMC and benefit from:

- fast, convenient online submission

- thorough peer review by experienced researchers in your field

- rapid publication on acceptance

- support for research data, including large and complex data types

- gold Open Access which fosters wider collaboration and increased citations

- maximum visibility for your research: over $100 \mathrm{M}$ website views per year

At BMC, research is always in progress.

Learn more biomedcentral.com/submissions 